\title{
Suppression of Proinflammatory Cytokines in Functionalized Fullerene-Exposed Dermal Keratinocytes
}

\author{
Jun Gao, ${ }^{1}$ Hsing-Lin Wang, ${ }^{2}$ and Rashi Iyer ${ }^{1}$ \\ ${ }^{1}$ Biosciences Division, Los Alamos National Laboratory, M888, TA 43, HRL-2, Los Alamos, NM 87545, USA \\ ${ }^{2}$ Chemistry Division, Los Alamos National Laboratory, J567, TA 46, Los Alamos, NM 87545, USA
}

Correspondence should be addressed to Rashi Iyer, rashi@lanl.gov

Received 1 October 2009; Accepted 24 November 2009

Academic Editor: Huisheng Peng

Copyright ( $) 2010$ Jun Gao et al. This is an open access article distributed under the Creative Commons Attribution License, which permits unrestricted use, distribution, and reproduction in any medium, provided the original work is properly cited.

\begin{abstract}
Initial experiments using differentially functionalized fullerenes, $C D-\mathrm{C}_{60}$, hexa- $\mathrm{C}_{60}$, and tris- $\mathrm{C}_{60}$, suggested a properties dependent effect on cytotoxic and proliferative responses in human skin keratinocytes. In the present study we investigated the cytokine secretion profile of dermal epithelial cells exposed to functionalized fullerenes. Keratinocyte-derived cytokines affect homing and trafficking of normal and malignant epidermal immune as well as nonimmune cells in vivo. These cytokines are critical for regulating activation, proliferation, and differentiation of epidermal cells. Our results indicate that tris- $\mathrm{C}_{60}($ size range $<100 \mathrm{~nm})$ significantly reduces inflammatory cytokine release in a dose- and time-dependent manner. In contrast $\mathrm{CD}_{-} \mathrm{C}_{60} \mathrm{demonstrated}$ a relatively pro-inflammatory cytokine response, while hexa- $\mathrm{C}_{60}$ did not significantly perturb cytokine responses. Physical and chemical characterizations of these engineered nanomaterials suggest that the disparate biological responses observed may potentially be a function of the aggregation properties of these fullerenes.
\end{abstract}

\section{Introduction}

Engineered nanomaterials have been wildly used for diagnostic therapy and drug delivery based on their unique properties, such as size and charge $[1,2] . \mathrm{C}_{60}$-derived fullerenes are carbon allotropes whose physical and chemical properties are easily manipulatable making them attractive targets for clinical and industrial applications [3, 4]. However, unmodified fullerenes tend to form large aggregates due to their high aspect ratio and the strong van der Waals attraction between them, resulting in limited solubility in aqueous media thus restricting their applications. Consequently, drug development platforms as well as other commercial uses (e.g., for composites) have focused on derivatizing native $\mathrm{C}_{60}$ fullerene molecules rendering it soluble. This not only broadens the scope of applications but also makes fullerenes more available to and interactive with biological systems, raising concerns about the potential toxicity of these materials. Also, the claimed mass production of fullerenes by Frontier Carbon Corporation makes it a possible workplace hazard.
In the current study we used three hydrophilic fullerenes derivatives, hexa-dicarboxyl fullerene, trisdicarboxyl fullerene, and gamma $(\gamma)$-cyclodextrin caged $\mathrm{C}_{60}$. Encapsulation of $\mathrm{C}_{60}$ by $\gamma$-cyclodextrin enhances the solubility of $\mathrm{C}_{60}$ without impacting the physicochemical properties of native $\mathrm{C}_{60}$, thus serving as an appropriate control [5]. While chemical functionalization of $\mathrm{C}_{60}$ by the addition of carboxyl groups on the surface renders normally insoluble fullerenes soluble in aqueous media it also alters the electronic and physical properties of fullerenes. The physicochemical properties of the fullerene influence its interactions with cells and biological molecules. Studies have shown that nanomaterials can penetrate through skin and induce localized or even systemic biological responses [6]. In the present study human epidermal keratinocyte (HEK) cells were utilized to simulate the primary route of occupational dermal exposure and potential topical applications of fullerene derivatives. Skin epidermis is a first line of defense against pathogens and other environmental insults. Keratinocytes are the major cell type in human epidermis and are the primary responders to exogenous 
insults generating a variety of different cytokines greatly influencing the inflammatory dermal response [7-9]. In a previous study (manuscript submitted), we performed a suite of cellular endpoint analysis to determine the response of epidermal keratinocyte (HEK) to these distinctly derivatized fullerenes. A comparative analysis of the cellular responses elicited by these functionalized fullerenes indicated that tris- $\mathrm{C}_{60}$ induced a differential response in HEK cells relative to either $\mathrm{CD}-\mathrm{C}_{60}$ or hexa $\mathrm{C}_{60}$ fullerenes. Furthermore, the results presented herein suggest that engineered fullerene derivatives can dramatically alter the apoptotic and proliferative responses of HEK cells. Since cytokines influence viability, proliferation and differentiation of keratinocytes in vivo and are pivotal in the recruitment of immune cells [10] and the ensuing inflammatory response, we further evaluate the cytokine response of human epidermal keratinocyte (HEK) cells to modified fullerenes.

\section{Materials and Methods}

2.1. Chemicals and Reagents. All reagents used in the study were special grade commercial products purchased from Invitrogen (Carlsbad, CA) and Sigma-Aldrich (Saint Louis, $\mathrm{MO}$ ), unless otherwise stated. The cytokine kits were purchased from BD Biosciences (San Diego, CA) and Antigenix America (Huntington Sta., NY). The cytokine array kit was obtained from RayBiotech (Norcross, GA).

2.2. Preparation of Fullerene and Its Derivatives. The watersoluble carboxyfullerenes $\mathrm{C}_{60}$ substituted with a total of 12 (hexa- $\mathrm{C}_{60}$ ) or 6 (tris- $\mathrm{C}_{60}$ ) carboxyl groups (see Supplement 1 available at doi: 10.1155/2010/41640) and $\gamma$-cyclodextrin$\mathrm{C}_{60}$ fullerene molecule (referred to as $\mathrm{CD}-\mathrm{C}_{60}$ ) were synthesized for this study as described in [11].

Preparation of fullerene derivative working solutions: tris or hexa- $\mathrm{C}_{60}$ fullerene was added to sterilized distilled water and $\mathrm{pH}$ adjusted to 7.0 to create a stock solution of $2 \mathrm{mg} / \mathrm{mL}$. The stock solutions were stored at $4{ }^{\circ} \mathrm{C}$ until use. Before the experiment, the stock solutions were vortexed for 3 minutes, then sonicated for 10 minutes to break up aggregates and form a uniform suspension. From this stock, serial dilutions of 25,50 , and $100 \mu \mathrm{g} / \mathrm{mL}$ in cell growth media were prepared and used to treat the cells.

2.3. Cell Culture. Human epidermal keratinocyte (HEK) cells (ATCC CRL-2404) were grown in defined keratinocyte serum free medium (SFM) (Cat No. 10785, Invitorgen, Carlsbad, CA) supplemented with $1 \mathrm{~mL}$ Defined Keratinocyte-SFM growth supplement (Cat No. 10784, Invitrogen) in a $37^{\circ} \mathrm{C}$ incubator with a humidified atmosphere and $5 \% \mathrm{CO}_{2}$. HEK cells were either cultured in flat-bottom 96-well $\left(1.5 \times 10^{4}\right.$ cells/well $)$ or 6 -well $\left(2.0 \times 10^{5}\right.$ cells/well $)$ cell culture plates depending on the end-point to be assayed. Cells were treated with caged- $\mathrm{C}_{60}$ or carboxyfullerenes at concentrations of $25 \mu \mathrm{g} / \mathrm{mL}, 50 \mu \mathrm{g} / \mathrm{mL}$, and $100 \mu \mathrm{g} / \mathrm{mL}$ in warm media for various time points. A control sample of untreated cells was cultured, washed, and incubated for the same time points for each experiment. The cells were incubated at $37^{\circ} \mathrm{C}$ with a humidified atmosphere and $5 \%$ $\mathrm{CO}_{2}$ during exposure.

2.4. Apoptosis Assay. Apoptotic cell death was analyzed by photometric enzyme-immunoassay kit (Cat. No. 11774425001, Roche Applied Science, Mannheim, Germany). Briefly, HEK cells were plated at a population of approximately $1.0 \times 10^{5}$ cells/well in 6-well cell culture plates. The cells were exposed to caged- $\mathrm{C}_{60}$ and carboxyfullerenes for 24 hours. Camptothecin (CAM, $1 \mu \mathrm{M}$ ) (Cat. No. 1039-1, BioVision) was used as a positive control for apoptosis induction. After treatment the cell culture plates were centrifuged for 10 minutes at $200 \times \mathrm{g}$. At the end of each time point the cells were analyzed for apoptosis. The sample absorbance was measured with an ELISA plate reader Synergy 2 multimode microplate reader (BioTek Instruments, Inc., Winooski, VT) at $405 \mathrm{~nm}$ and $490 \mathrm{~nm}$. To confirm the ELISA results, treated cells were dual labeled with acridine orange/ethidium bromide $(\mathrm{AO} / \mathrm{EB})$ dyes to visualize apoptotic cells. Equal volumes of $100 \mu \mathrm{g} / \mathrm{mL}$ AO and EB in DPBS were mixed to stain the treated cells. Stained cells were immediately analyzed using a fluorescence microscope with $20 \times$ objective (Zeiss Axiophot, Carl Zeiss, Germany) and image-Pro Plus software (Ver. 6.2, Media Cybernetics, Silver Spring, MD). Apoptotic cells were delineated with orange nuclei, and live cells appear uniformly green.

2.5. Cell Proliferation Assay. The cell proliferation reagent WST-1 (a tetrazolium salt cleaved in viable cells) (Cat. No. MK400, TaKaRa BIO Inc., Madison, WI) was used to quantify cell proliferative activity. Briefly, HEK cells were seeded at $5 \times 10^{4}$ cells per well in 96-well plates and allowed to reattach for 24 hours prior to exposure to fullerenes. After 24 hours, cells were washed twice. $10 \mu \mathrm{l}$ WST- 1 and $100 \mu \mathrm{l}$ fresh warm media were added to each well and incubated for an additional 2 hours. Cell proliferation was assessed by measuring the absorbance at $450 \mathrm{~nm}$ and $600 \mathrm{~nm}$ using a microplate reader.

2.6. Cytokine Antibody Array. The levels of cytokines released into cell culture media by functionalized fullerenes were measured using RayBio Human Cytokine Antibody Array III (Cat. No. AAH-CYT-3, RayBiotech). This antibody array matrix can simultaneously detect 44 cytokines, chemokines and growth factors (Figure 3 ). The samples were analyzed according to the manufacturer's instructions. Briefly, cell culture medium from control and fullerene $(50 \mu \mathrm{g} / \mathrm{mL})$ treated groups was collected after $4,8,12$, and 24 hours. The antibody array membranes were blocked using $2 \mathrm{~mL}$ of $1 \times$ blocking buffer at room temperature for 30 minutes in an 8 -well tray. Subsequently, $1 \mathrm{~mL}$ of cell culture medium was added to each well, and then incubated at room temperature for 2 hours. After incubation, the membrane was washed three times with washing buffer I for 5 minutes each, and then washed twice using washing buffer II for 5 minutes each. The membranes were incubated with biotin-conjugated 
anticytokine antibodies for 2 hours, followed by HRP-labeled strepavidin incubation for 2 hours at room temperature. Cytokines were detected with supersignal west dura extended duration substrate (Cat. No. 34-75, Thermo Scientific Pierce, Rockford, IL) and visualized with ChemiDoc imaging system (BioRad, Hercules, CA). The intensity level of each spot was determined using Quality One Software (BioRad). The positive controls on membrane were used to normalize the signal intensity of individual cytokines.

2.7. Individual Cytokine Detection. HEK cells were seeded in 6-well plates at a concentration of $2 \times 10^{4}$ cells/well and treated with various concentrations of fullerene derivatives for 2, 4, 8, 12, 24, and 48 hours. At the end of each time point, cell supernatants were harvested for cytokine release analysis. The concentration of human IL- $1 \beta$, IL-6, IL- 8 , tumor necrosis factor $\beta$ (TNF- $\beta$ ), MCP-1 (Cat. No. 557953, 555220, 555244,550995 , and 555179, BD biosciences), GRO- $\beta$, GRO$\gamma$, and RANTES (Cat. No. RHF810CK, RHF820CK and RHF520CKC, Antigenix America) levels in the media were assessed by cytokine Enzyme-Linked Immunosorbent Assay (ELISA) kits according to the manufacturer's instructions. Briefly, the 96-well plates (Nunc) were coated overnight at $4^{\circ} \mathrm{C}$ with capture antibody diluted in coating buffer (BD OptEIA reagent set B, Cat. No. 550534). Plates were washed with freshly made wash buffer (PBS with $0.05 \%$ Tween-20), and blocked with $200 \mu$ l assay dilute for 1 hour. Subsequently wells were washed 3 times standard cytokines and test samples were added to each well in triplicate $(100 \mu \mathrm{L} /$ well $)$ and incubated for 2 hours at room temperature. Bound cytokines were detected after 1 hour with working detector ( $100 \mu \mathrm{l}$, detection antibody + horseradish peroxidase conjugated streptavidin). Finally, color was developed using substrate solution and stopping reagents. Absorbance was measured at $450 \mathrm{~nm}$, and the background noise was read at $570 \mathrm{~nm}$. Cytokine concentrations were determined using the standard curve in the same plate.

2.8. Statistical Analysis. Data were analyzed by Sigma Stat software (Jandel Science, San Rafael, CA). The statistical differences among groups were determined by one-way analysis of variance (ANOVA) and/or Student's $t$-test. A Dunnett correction was used for multiple comparisons. The values were expressed as mean \pm SEM. A $P$-value $<.05$ was considered a statistically significant difference.

\section{Results and Discussion}

3.1. Physicochemical Properties of Fullerenes. The physicochemical characteristics of engineered nanomaterials greatly impact their properties eventually influencing their ability to interact with biological systems. As we have shown in the current study $C D-\mathrm{C}_{60}$, hexa- $\mathrm{C}_{60}$ and tris- $\mathrm{C}_{60}$ can induce diametrically opposite cellular and molecular responses. Using electrochemical characterization, UV-Vis spectra, dynamic light scattering, and atomic force microscopy, we obtained the following information about the physical and chemical properties of these fullerenes: (1) reduction potential of
CD- $\mathrm{C}_{60}$, hexa- $\mathrm{C}_{60}$, and tris- $\mathrm{C}_{60}$ versus $\mathrm{Ag} / \mathrm{AgCl}$ is -0.98 , -1.25 , and $-1.12 \mathrm{~V}$, respectively, (2) both the hexa- $\mathrm{C}_{60}$ and CD- $\mathrm{C}_{60}$ were highly polydisperse with a range of particles from $20 \mathrm{~nm}$ to micron sized, and (3) tris- $\mathrm{C}_{60}$ is relatively monodisperse with particle size from 100 to $160 \mathrm{~nm}$. The chemical modifications of fullerenes appeared to impact the redox properties and aggregation properties of the fullerenes.

3.2. Functionalized Fullerene-Induced Apoptosis. The previous studies in our laboratory have shown that fullerenes can regulate apoptosis in macrophage-like THP1 cells [11]. We therefore examined the ability of these fullerenes to induce cellular apoptosis in HEK cells. Programmed cell death was quantified after treatment with $\mathrm{CD}-\mathrm{C}_{60}$, hexa- $\mathrm{C}_{60}$ and tris- $\mathrm{C}_{60}(25,50$, and $100 \mu \mathrm{g} / \mathrm{mL})$ for 6 and 24 hours. Cells were treated with camptothecin (CAM) as a positive control. Using an ELISA assay, the amount of cytoplasmic nucleosomes, an indicator of apoptosis, was measured in each sample. Though all three fullerenes appeared to inhibit basal apoptotic cell death, tris- $\mathrm{C}_{60}$ caused over a $50 \%$ decrease in the number of apoptotic cells at all concentration tested (Figure 1(a)). Moreover, unlike CD-C 60 , and hexa$\mathrm{C}_{60}$, tris- $\mathrm{C}_{60}$ protected the cells from camptothecin-induced apoptotic cell death in a dose dependent manner, and completely inhibiting apoptosis at $100 \mu \mathrm{g} / \mathrm{mL}$ (Figure 1(b)). These results were confirmed morphologically using AO/EB fluorescent staining (data not shown). Apoptosis plays a critical role in the development and maintenance of homeostasis and in the maturation of organ systems [12]. Perturbation of this naturally occurring physiological process has been observed in several disease states. Dysregulation or failure of normal apoptosis contributes to the transformation of cells and provides a growth advantage to cancer cells [13]. The observed antiapoptotic function of CD- $\mathrm{C}_{60}$ and hexa- $\mathrm{C}_{60}$, and the ability of tris- $\mathrm{C}_{60}$ to inhibit apoptosis by extraneous agents raise concerns about their safety. Conversely, tris- $\mathrm{C}_{60}$ could potentially be used to prevent premature neuronal degeneration caused by apoptotic cell death as has been previously suggested in [14].

\subsection{Effect of Functionalized Fullerene on HEK Cell Prolifera-} tion. Further we examined the proliferative response of cells on exposure to fullerenes. Cellular proliferation in HEK cells was quantified using a nonradioactive WST-1 assay. This tetrazolium salt is cleaved to a soluble formazan dye by the succinate-tetrazolium reductase which is active only in viable cells. The quantity of formazan dye is related directly to the number of metabolically active cells. While no significant changes were observed in the proliferation capacity of cells treated with $\mathrm{CD}-\mathrm{C}_{60}$ and hexa- $\mathrm{C}_{60}$, there was a significant decrease in the percentage of proliferating cells in the tris$\mathrm{C}_{60}$ treated cells (Figure 2). These results indicate that not only can tris- $\mathrm{C}_{60}$ perturb apoptotic mechanisms but it may also inhibit cell cycle progression, preventing cell division. Since cellular senescence is defined by the inability of cells to proliferate and occasionally to be resistant to apoptosis one can speculate that tris- $\mathrm{C}_{60}$ may potentially induce senescence in HEK cells. Studies are ongoing to examine this response. 

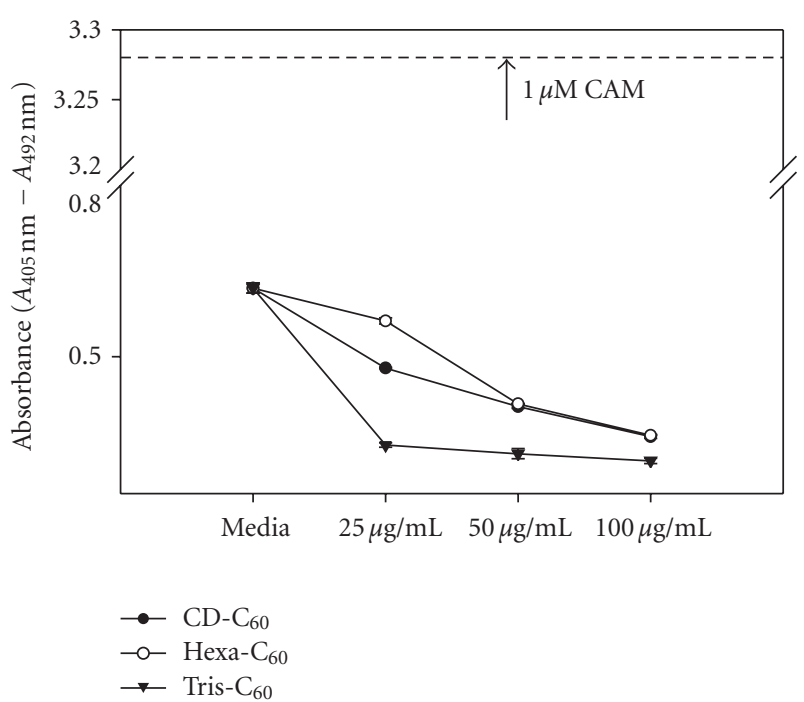

(a)

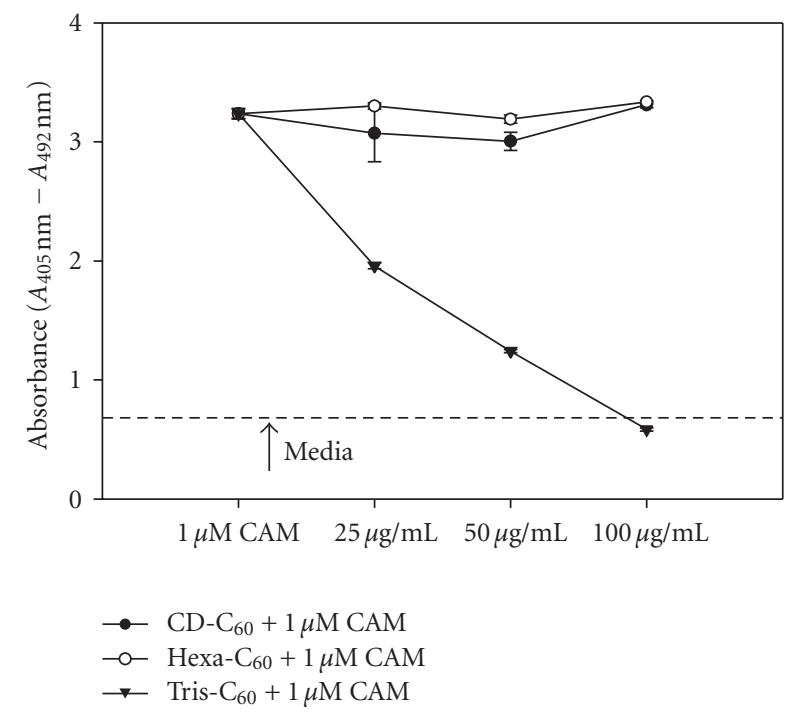

(b)

Figure 1: Evaluation of apoptotic response in HEK cells. (a) Cells were treated with fullerene and its derivatives for 24 hours. Apoptotic cell death was quantified by photometric enzymeimmunoassay. Media and $1 \mu \mathrm{M}$ camptothecin (dash line) were used as negative and positive controls, respectively. (b) Cells were pretreated with fullerene and its derivatives for 2 hours, then cotreated with $1 \mu \mathrm{M}$ camptothecin for 24 hours. Relative change in apoptosis was compared to untreated cells (Media, dash line), and camptothecin (CAM). Values are presented as means \pm SEM of triplicate cultures from two individual samples in each treatment group.

3.4. Fullerene-Mediated Cytokine Response. Insult mediated release of immunoregulatory molecules or cytokines primarily produced by keratinocytes are capable of initiating an immune response in the epidermis [15]. IL-1, which is constitutively produced and stored by keratinocytes, is released on damage to these cells and in turn stimulates the production of other cytokines such as, IL-6, IL-8, GM-CSF,

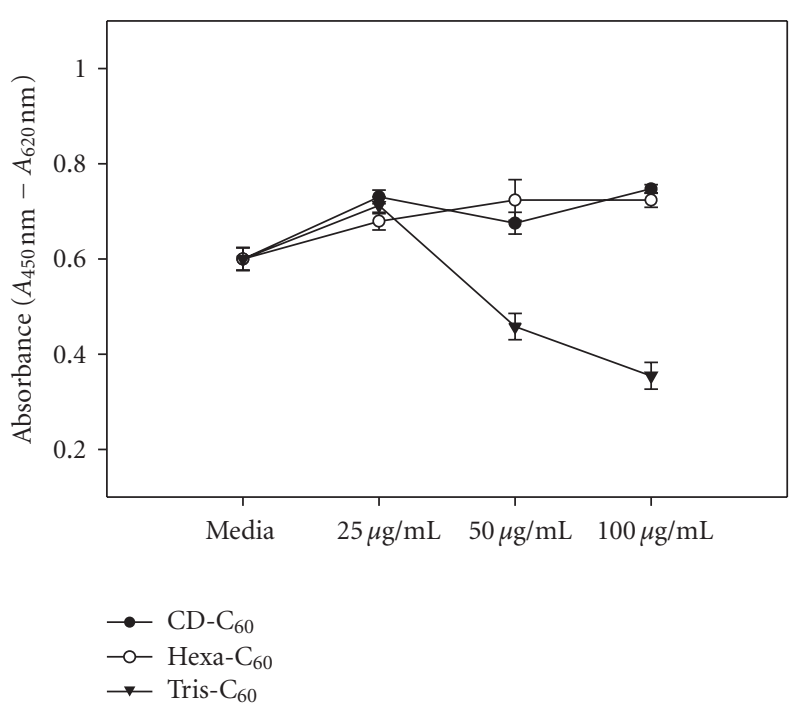

FIGURE 2: Detection of HEK cell proliferation. Proliferation was determined using the WST-1 proliferation assay. HEK cells were treated with fullerene derivatives for 24 hours; cells cultured with medium were used as control. Data are means \pm SEM. of quadruplicate cultures in each treatment group. Independent experiments were performed in triplicate.

and TNF- $\alpha$ amongst others [16]. Therefore, keratinocytes play a major role in the skin immune response. Moreover, physiological responses including apoptosis and proliferation are mediated by these very cytokines and play a deterministic role in the evolution and the integrity of the epidermal layer. We examined the secretion profile of cytokines in HEK cells exposed to the three different fullerenes using a cytokine antibody array to measure 44 different cytokines (Figure 3). HEK cells were treated with $50 \mu \mathrm{g} / \mathrm{mL}$ fullerenes for $4,8,12$ and 24 hours. Interestingly, tris- $\mathrm{C}_{60}$ significantly suppressed the major proinflammatory cytokines IL- 6 and IL-8 and reduced TNF- $\beta$, RANTES, and GRO release as well. However, a notable increase in IL$1 \beta$ levels was observed in a time-dependent manner. In contrast, CD- $\mathrm{C}_{60}$ caused a significant increase in IL- 6 and IL-8 release, but reduced TNF- $\beta$ levels. Unexpectedly, the cytokine profiles for hexa- $\mathrm{C}_{60}$ treated groups were similar to medium control.

3.5. Fullerene Derivatives Alter IL-1 $\beta, I L-6$, and IL-8 Release in HEK Cells. To determine the kinetics of the observed cytokine response and to confirm the array results we utilized single cytokine ELISA kits to assess extracellular cytokine levels from 2 to 48 hours. The cytokine array results indicate that functionalized fullerenes induce IL- $1 \beta$ release, but not IL- $1 \alpha$. We quantified IL- $1 \beta$ levels after cells were treated with fullerenes for 24 hours. A dose dependent induction of IL- $1 \beta$ release was observed in tris- $\mathrm{C}_{60}$ treated cells. No significant difference was noted in the $\mathrm{CD}-\mathrm{C}_{60}$ and hexa- $\mathrm{C}_{60}$ treated cells compared to medium control (Figure 4). It has been well demonstrated that normal human epidermal cells can produce interleukin-1 (IL-1) and TNF $[17,18]$. Both these 


\begin{tabular}{|c|c|c|c|c|c|c|c|c|c|c|c|c|}
\hline & 1 & 2 & 3 & 4 & 5 & 6 & 7 & 8 & 9 & 10 & 11 & 12 \\
\hline A & Pos & Pos & Neg & Neg & ENA-78 & GCSF & GM-CSF & GRO & GRO- $\alpha$ & $1-309$ & IL-1 $\alpha$ & IL-1 $\beta$ \\
\hline B & Pos & Pos & Neg & Neg & ENA-78 & GCSF & GM-CSF & GRO & GRO- $\alpha$ & $1-309$ & IL-l $\alpha$ & IL-1 $\beta$ \\
\hline C & IL-2 & IL-3 & IL-4 & IL-5 & IL-6 & I L-7 & IL-8 & IL-I0 & IL-12 & IL-13 & \begin{tabular}{|l|} 
IL-15 \\
\end{tabular} & IFN- $\gamma$ \\
\hline D & IL-2 & IL-3 & IL-4 & IL-5 & IL-6 & I L-7 & IL-8 & IL-I0 & IL-12 & IL-13 & IL-15 & IFN- $\gamma$ \\
\hline $\mathrm{E}$ & $\mathrm{MCP}-1$ & MPC-2 & MCP-3 & MCSF & MDC & MIG & MIP-1 $\delta$ & RANTES & SCF & SDF-1 & TARC & TGF- $\beta 1$ \\
\hline $\mathrm{F}$ & MCP-1 & MPC-2 & MCP-3 & MCSF & MDC & MIG & MIP-1 $\delta$ & RANTES & SCF & SDF-1 & TARC & TGF- $\beta 1$ \\
\hline 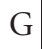 & TNF- $\alpha$ & TNF- $\beta$ & EGF & IGF-1 & Angiagenin & Onco. M & Throm. & VEGF & PDGF BB & Leptin & Neg & Pos \\
\hline & TNF- $\alpha$ & TNF- $\beta$ & EGF & IGF-1 & Angiagenin & Onco. M & Throm. & VEGF & PDGF BB & Leptin & Neg & Pos \\
\hline
\end{tabular}

(a)
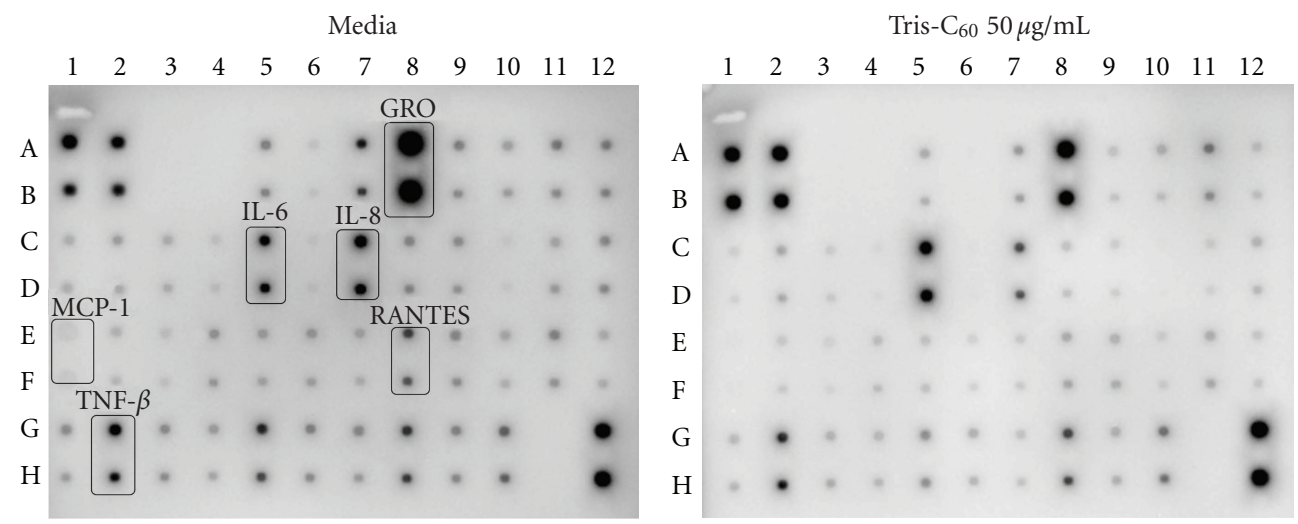

$\mathrm{CD}-\mathrm{C}_{60} 50 \mu \mathrm{g} / \mathrm{mL}$
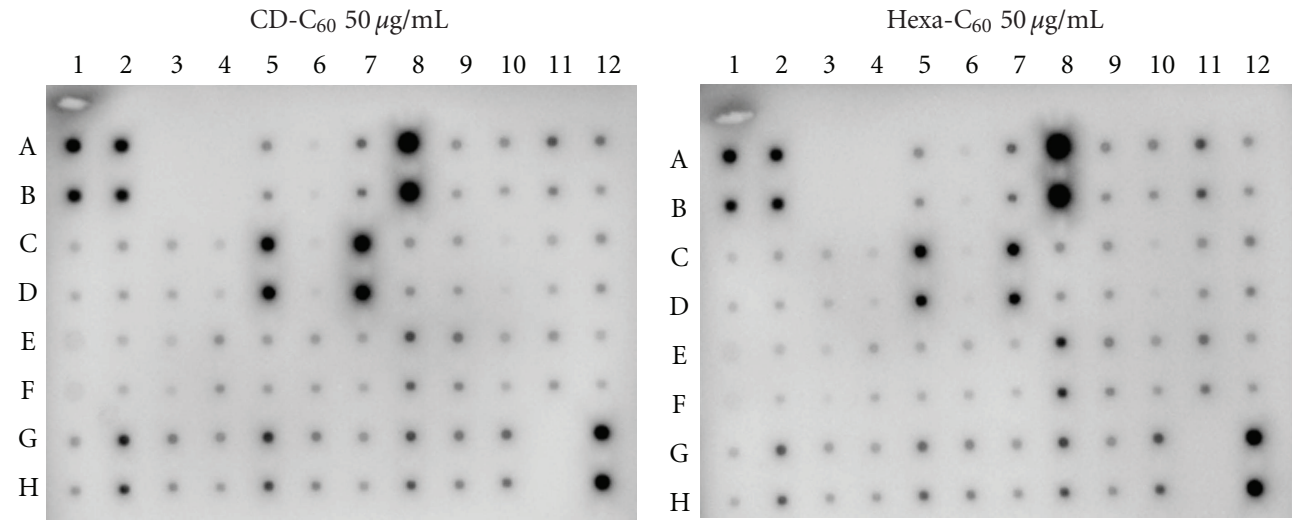

(b)

Figure 3: Cytokine array analysis in HEK cells treated with functionalized fullerene. (a) Antibody spotting map on the antibody array membrane. Each cytokine is represented by duplicate spots. Pos: positive control; Neg: negative control. (b) Detection of cytokines on membrane antibody array by chemiluminscence. HEK cells were treated with $50 \mu \mathrm{g} / \mathrm{mL}$ fullerenes for $4,8,12$, and 24 hours. Images represent cytokine array from 24 hours fullerene treated HEK cell culture media.

cytokines act synergistically to orchestrate inflammatory responses and can also induce endothelial adhesion molecule (ICAM) expression critical for the adhesion of immune cells to the endothelial surface $[14,19]$. In addition, these keratinocyte-derived cytokines may enhance accumulation of diverse cytotoxic effector cells for the destruction of keratinocytes. Release of IL- 1 by damaged keratinocytes induces the production of proinflammatory cytokines, IL-6 and IL-8. IL-6 is produced by keratinocytes in response to skin injuries and can play a dominant role in dermal inflammatory diseases [20]. IL-8 is a major neutrophil chemoattractant and an important mediator of cutaneous inflammatory events, involved in lymphocyte migration and infiltration in human skin [21]. Conflictingly, in our array results, we observed a decrease in both IL- 6 and Il-8 in tris- $\mathrm{C}_{60}$ exposed cells. These results were further confirmed by cytokine-specific ELISAs, wherein, we saw a sharp decrease in the IL-6 levels as early as 2 hours, continuing to decrease to 48 hours in tris$\mathrm{C}_{60}$ treated cells. In contrast, IL- 6 release was significantly increased in a dose dependent manner after 8 hours of CD- $\mathrm{C}_{60}$ treatment in HEK cells. No significant differences occurred between hexa- $\mathrm{C}_{60}$ treated and untreated media control group (Figure 5(a)). Similar IL-8 responses were noted (Figure 5(b)), where CD-C 60 upregulates IL-8 release 


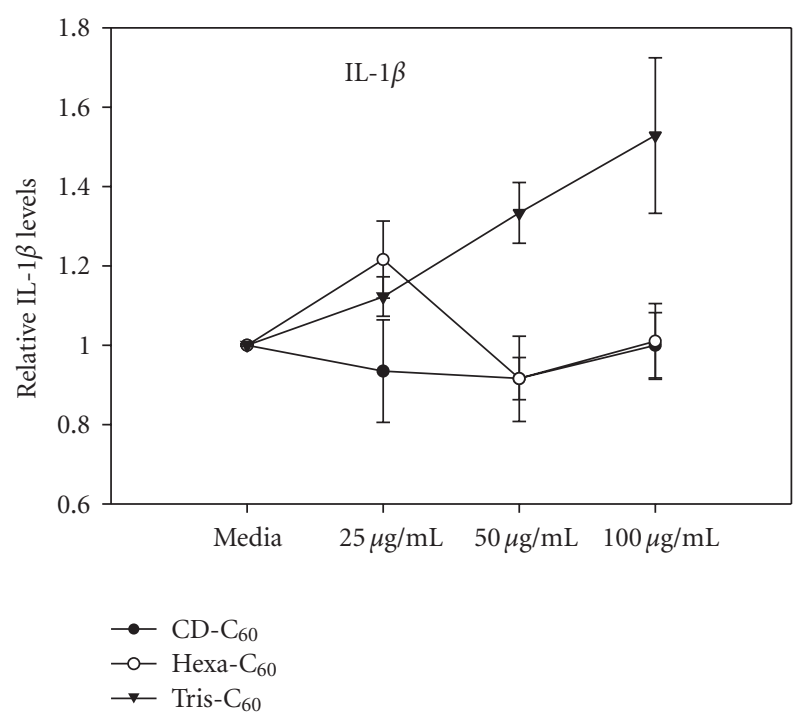

FIGURE 4: Effect of fullerene derivatives on IL-1 $\beta$ release in HEK cells. HEK cells were treated with the different doses of fullerene derivatives for 24 hours. Cytokine ELISA detection kits were used to evaluate IL- $1 \beta$ cytokines. The concentration of released cytokines was calculated by cytokine standard curve in the same measuring plate. Data are means \pm SEM. of quadruplicate cultures in each treatment group.

and tris- $\mathrm{C}_{60}$ suppresses IL-8 release. Interestingly, release of IL- 8 was significantly decreased in a dose-dependent manner after 2 hours of hexa- $\mathrm{C}_{60}$ treatment. $\mathrm{CD}-\mathrm{C}_{60}$ induction of proinflammatory cytokines IL- 6 and IL-8 suggests that CD$\mathrm{C}_{60}$ may potentially induce an inflammatory response in HEK cells $[10,22]$.

Interestingly, studies with mouse embryonic fibroblasts undergoing senescence demonstrated an increase in the expression and secretion of IL- $1 \beta$ and the involvement of the IL- $1 \beta$ signaling pathway in activation of p38 linked cellular senescence [23] implicating a role for IL-1 $\beta$ in this phenomena. As discussed earlier, senescent cells are often characterized by their resistance to apoptosis and their inability to proliferate. Both of these responses were observed in tris- $\mathrm{C}_{60}$ treated cells, accompanied with a simultaneous enhancement in IL- $1 \beta$ levels. These responses were noted in a background of attenuated levels of proinflammatory cytokines IL- 6 and IL-8, suggesting that tris- $\mathrm{C}_{60}$ may be inducing senescence in these cells.

3.6. Fullerene Derivatives Alter TNF- $\beta$, GRO , and RANTES Release in HEK Cells. In the cytokine array study, TNF- $\alpha$ was not affected by fullerene treatment. Interestingly, TNF$\beta$ (lymphotoxin alpha) was inhibited on exposure to tris, hexa and $C D-C_{60}$, and this result was confirmed by a TNF$\beta$ ELISA assay (Figure 6(a)). TNF- $\beta$ is a potent mediator of inflammatory and immune responses. Like TNF- $\alpha$, TNF- $\beta$ is involved in the regulation of various biological processes including cell proliferation, differentiation, apoptosis, lipid metabolism, coagulation, and antiviral responses.

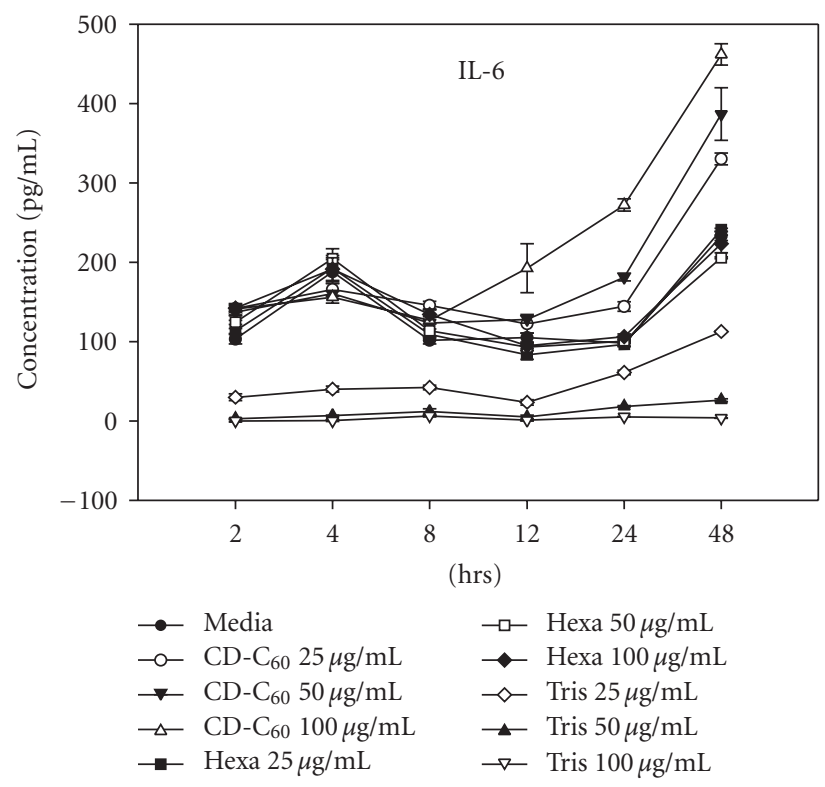

(a)

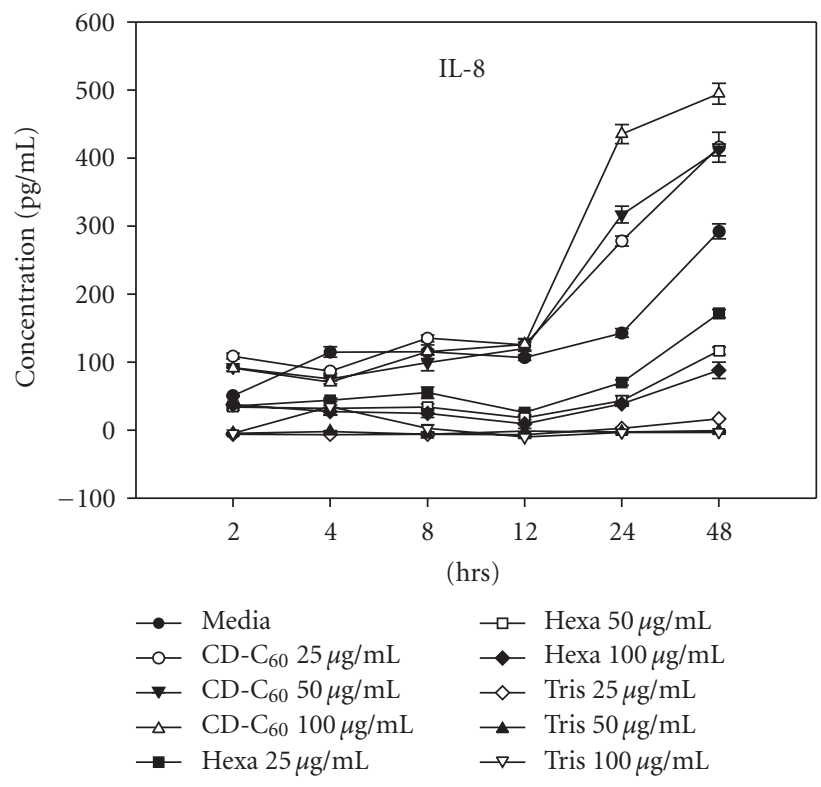

(b)

Figure 5: Effect of fullerene derivatives on IL-6 and IL-8 release in HEK cells. Cells were treated with fullerene derivatives for 2, 4, 8, 12, 24, and 48 hours. Cytokine ELISA detection kits were used to evaluate cytokines in culture media. IL-6 (a) and IL-8 (b) releases were significantly altered by fullerene derivatives. Data are means \pm SEM. of quadruplicate cultures in each treatment group.

GRO, also referred to as MGSA for melanoma growthstimulatory activity, stimulates keratinocyte proliferation and migration, and angiogenesis in cutaneous wound healing [24]. Members of the GRO family, GRO $\alpha, \mathrm{GRO} \beta$ and $\mathrm{GRO} \gamma$, exhibit some functional redundancy. A decrease in total GRO levels was observed in tris- $\mathrm{C}_{60}$ treated cells by the cytokine antibody array assay, but not GRO $\alpha$. We further evaluated GRO $\beta$ and $\mathrm{GRO} \gamma$ levels using the ELISA 


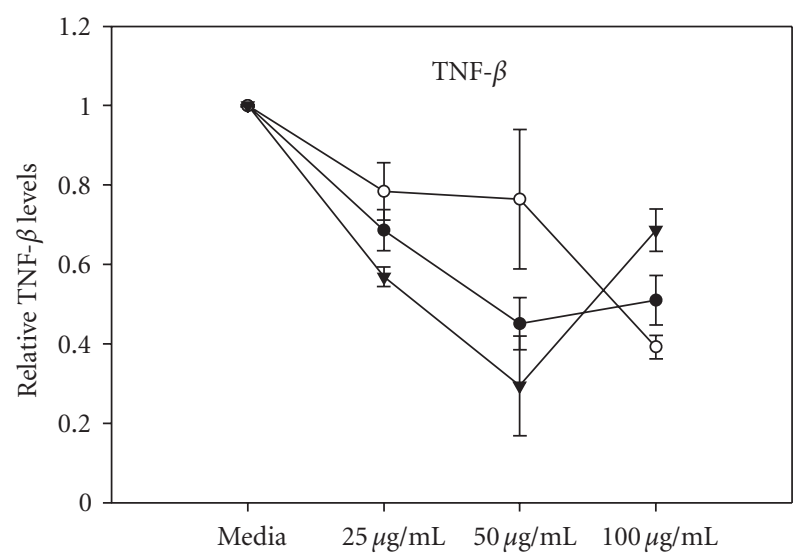

(a)

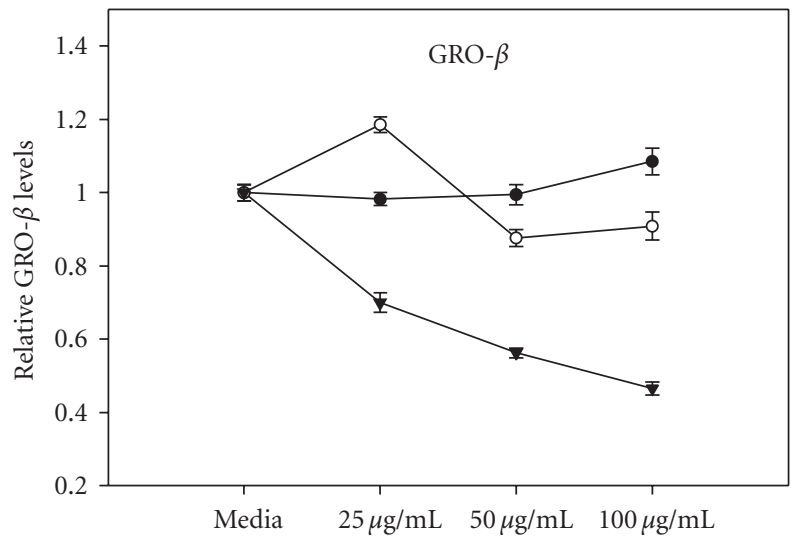

(b)

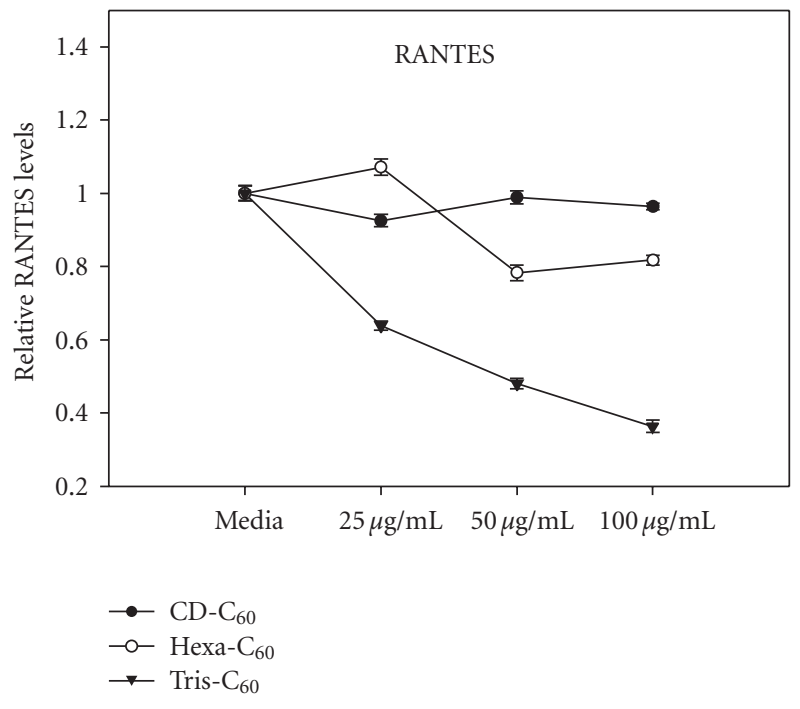

(c)

FIGURE 6: Effect of fullerene derivatives on TNF- $\beta$, GRO $\beta$ and RANTES release in HEK cells. Cells were treated with fullerene derivatives for 24 hours. Cytokine ELISA detection kits were used to evaluate cytokines. TNF- $\beta$ (a), GRO $\beta$ (b) and RANTES (c) release were significantly altered by fullerene derivatives. Data are means \pm SEM. of quadruplicate cultures in each treatment group.

construction kit. No changes in $\mathrm{GRO} \gamma$ were noted with either of the functionalized fullerenes (data not shown). However, GRO $\beta$ was suppressed by tris- $\mathrm{C}_{60}$ treatment (Figure $6(\mathrm{~b})$ ). $\mathrm{CD}-\mathrm{C}_{60}$ and hexa- $\mathrm{C}_{60}$ did not significantly affect $\mathrm{GRO} \beta$ secretion.

RANTES, or Regulated on Activation Normal T Cell Expressed and Secreted also called CCL5, is one of the chemokines produced by epidermal keratinocytes that might play an important role in the pathogenesis of cutaneous inflammatory disorders $[25,26]$. It is predominantly chemotactic for $\mathrm{T}$ cells and is involved in the recruitment of T lymphocytes, eosinophils, basophils, and leukocytes to inflammatory sites [27]. Here again secretion of RANTES was significantly downregulated by tris- $\mathrm{C}_{60}$ but was unaltered in $\mathrm{CD}-\mathrm{C}_{60}$ and hexa- $\mathrm{C}_{60}$ treated cells suggesting that $\mathrm{CD}-\mathrm{C}_{60}$ and hexa- $\mathrm{C}_{60}$ do not induce an inflammatory response (Figure 6(c)). However, tris- $\mathrm{C}_{60}$ appears to decrease the basal levels of RANTES secretion in HEK cells suggesting a downregulation of normal inflammatory responses and potentially an immunosuppressive function.

3.7. Fullerene Derivatives Did Not Affect MCP-1 Release in HEK Cells. Monocyte chemoattractant protein-I (MCP1 ) is a chemoattractant for monocytes, macrophages, and basophils, but not neutrophils [28]. MCP-1 has been implicated in regulating the expression of adhesion molecules and of some cytokines [29]. It is an important mediator in allergic inflammation [30]. The role of MCP-1 in both inflammatory diseases and normal tissue homeostasis is not clear. MCP-1 stimulates both chemotaxis of monocytes and several cellular events associated with chemotaxis, including $\mathrm{Ca}^{++}$flux and expression of integrins [31-33]. As shown in Figure 7, functionalized fullerenes did not alter MCP-1 levels even after 24 hours treatment. 


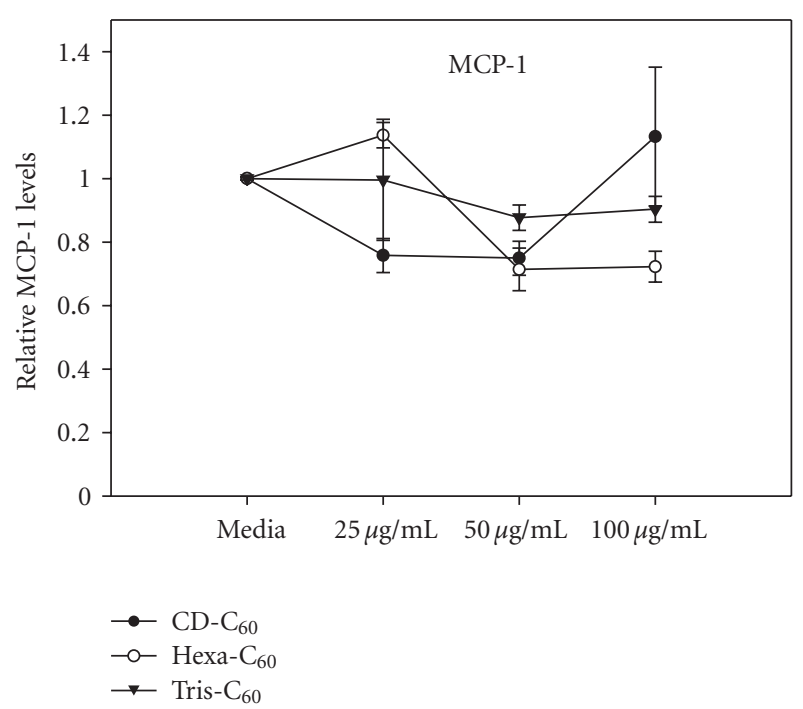

FIGURE 7: Effect of fullerene derivatives on MCP-1 release in HEK cells. Cells were treated with fullerene derivatives for 24 hours. Cytokine ELISA detection kits were used to evaluate cytokines. Data are means \pm SEM. of quadruplicate cultures in each treatment group.

\section{Conclusions}

The results of the cellular endpoint studies indicate that tris$\mathrm{C}_{60}$ can significantly reduce basal cell death and proliferation. Since apoptosis plays a critical role in maintaining cellular homeostasis, perturbation of this physiological response may potentially impact cell population dynamics and consequently organ-level responses [34]. A tris- $\mathrm{C}_{60}$ induced cell resting state may potentially explain the overall unaltered or reduction of inflammatory cytokine release such as, IL6, IL-8, GRO, TNF- $\beta$, RANTES, and MCP1. Our results demonstrate that $\mathrm{CD}-\mathrm{C}_{60}$, hexa- $\mathrm{C}_{60}$, and tris- $\mathrm{C}_{60}$ treatments elicit differential cytokine responses in HEK cells suggestive of a proinflammatory response by $\mathrm{CD}-\mathrm{C}_{60}$ (enhances IL6 and IL-8 levels) and an antiinflammatory response by tris- $\mathrm{C}_{60}$ (decreases all the inflammatory cytokines analyzed), while hexa- $\mathrm{C}_{60}$ did not induce any significant changes in cytokine levels except a reduction in IL-8. Collectively, the antiapoptotic and antiproliferative function, the decrease of key inflammatory and growth promoting cytokines combined with the increase in senescent-inducing IL- $1 \beta$ levels supports a prosenescent role for tris- $\mathrm{C}_{60}$. Keratinocytes constitute about $95 \%$ of the epidermis and play a pivotal role in the response of the dermal tissue to environmental insults. Functional dysregulation of these cells or even partial abolition of this population could have significant ramifications in the response of the skin tissue to injuries and microbial infections.

In summary, tris- $\mathrm{C}_{60}$ elicited different cellular responses when compared to either $\mathrm{CD}-\mathrm{C}_{60}$ or hexa- $\mathrm{C}_{60}$. In contrast, $\mathrm{CD}-\mathrm{C}_{60}$ and hexa- $\mathrm{C}_{60}$ induced relatively similar cellular responses. The observed difference in the biological responses of HEK cells to the three fullerenes could be tentatively attributed to the aggregation size of these particles.

\section{Acknowledgments}

This work was supported by Los Alamos National Laboratory, LDRD-DR program. This work was performed, in part, at the Center for Integrated Nanotechnologies, a U.S. Department of Energy, Office of Basic Energy Sciences user facility, Los Alamos National Laboratory (Contract DE-AC52-06NA25396), and Sandia National Laboratory (Contract DE-AC04-94AL85000). The authors thank Gabriel A. Montaño and Jennifer Martinez for their assistance with the physical characterization of the fullerenes.

\section{References}

[1] S. Bosi, T. Da Ros, G. Spalluto, and M. Prato, "Fullerene derivatives: an attractive tool for biological applications," European Journal of Medicinal Chemistry, vol. 38, no. 11-12, pp. 913-923, 2003.

[2] T. Da Ros, G. Spalluto, and M. Prato, "Biological applications of fullerene derivatives: a brief overview," Croatica Chemica Acta, vol. 74, no. 4, pp. 743-755, 2001.

[3] S. H. Friedman, P. S. Ganapathi, Y. Rubin, and G. L. Kenyon, "Optimizing the binding of fullerene inhibitors of the HIV-1 protease through predicted increases in hydrophobic desolvation," Journal of Medicinal Chemistry, vol. 41, no. 13, pp. 2424-2429, 1998.

[4] Z. Zhu, D. I. Schuster, and M. E. Tuckerman, "Molecular dynamics study of the connection between flap closing and binding of fullerene-based inhibitors of the HIV-1 protease," Biochemistry, vol. 42, no. 5, pp. 1326-1333, 2003.

[5] T. Andersson, K. Nilsson, M. Sundahl, G. Westman, and O. Wennerström, " $\mathrm{C}_{60}$ embedded in $\gamma$-cyclodextrin: a watersoluble fullerene," Journal of the Chemical Society, Chemical Communications, no. 8, pp. 604-606, 1992.

[6] L. W. Zhang, W. W. Yu, V. L. Colvin, and N. A. MonteiroRiviere, "Biological interactions of quantum dot nanoparticles in skin and in human epidermal keratinocytes," Toxicology and Applied Pharmacology, vol. 228, no. 2, pp. 200-211, 2008.

[7] K. Arai, F. Lee, A. Miyajima, S. Miyatake, N. Arai, and T. Yokota, "Cytokines: coordinators of immune and inflammatory responses," Annual Review of Biochemistry, vol. 59, pp. 783-836, 1990.

[8] J. Ye, A. Garg, C. Calhoun, K. R. Feingold, P. M. Elias, and R. Ghadially, "Alterations in cytokine regulation in aged epidermis: implications for permeability barrier homeostasis and inflammationI. IL-1 gene family," Experimental Dermatology, vol. 11, no. 3, pp. 209-216, 2002.

[9] R. C. McKenzie and D. N. Sauder, "The role of keratinocyte cytokines in inflammation and immunity," Journal of Investigative Dermatology, vol. 95, supplement 6, pp. 105S-107S, 1990.

[10] A. Gröne, "Keratinocytes and cytokines," Veterinary Immunology and Immunopathology, vol. 88, no. 1-2, pp. 1-12, 2002.

[11] M. Rebecca, W. Hsing-Lin, G. Jun, et al., "Impact of physicochemical properties of engineered fullerenes on key biological responses," Toxicology and Applied Pharmacology, vol. 234, no. 1, pp. 58-67, 2009.

[12] K. Nose, "Role of reactive oxygen species in the regulation of physiological functions," Biological and Pharmaceutical Bulletin, vol. 23, no. 8, pp. 897-903, 2000.

[13] C. B. Thompson, "Apoptosis in the pathogenesis and treatment of disease," Science, vol. 267, no. 5203, pp. 1456-1462, 1995. 
[14] M. Bisaglia, B. Natalini, R. Pellicciari, et al., "C3-fullerotris-methanodicarboxylic acid protects cerebellar granule cells from apoptosis," Journal of Neurochemistry, vol. 74, no. 3, pp. 1197-1204, 2000.

[15] D. N. Sauder, "The role of epidermal cytokines in inflammatory skin diseases," Journal of Investigative Dermatology, vol. 95, no. 5, pp. 27S-28S, 1990.

[16] C. A. Dinarello, "Proinflammatory cytokines," Chest, vol. 118, no. 2, pp. 503-508, 2000.

[17] S. Lisby and C. Hauser, "Transcriptional regulation of tumor necrosis factor- $\alpha$ in keratinocytes mediated by interleukin- $1 \beta$ and tumor necrosis factor- $\alpha$," Experimental Dermatology, vol. 11, no. 6, pp. 592-598, 2002.

[18] C. Ibisch, P. Bourdeau, C. Cadiot, J. Viac, and H. Gatto, "Upregulation of TNF- $\alpha$ production by IFN- $\gamma$ and LPS in cultured canine keratinocytes: application to monosaccharides effects," Veterinary Research Communications, vol. 31, no. 7, pp. 835-846, 2007.

[19] D. A. Norris, "Cytokine modulation of adhesion molecules in the regulation of immunologic cytotoxicity of epidermal targets," Journal of Investigative Dermatology, vol. 95, supplement 6, pp. 111S-120S, 1990.

[20] M. Chabot-Fletcher, J. Breton, J. Lee, P. Young, and D. E. Griswold, "Interleukin-8 production is regulated by protein kinase C in human keratinocytes," Journal of Investigative Dermatology, vol. 103, no. 4, pp. 509-515, 1994.

[21] J. M. Schröder, "Chemotactic cytokines in the epidermis," Experimental Dermatology, vol. 1, no. 1, pp. 12-19, 1992.

[22] E. Corsini and C. L. Galli, "Cytokines and irritant contact dermatitis," Toxicology Letters, vol. 102-103, pp. 277-282, 1998.

[23] N. Uekawa, A. Nishikimi, K.-I. Isobe, Y. Iwakura, and M. Maruyama, "Involvement of IL-1 family proteins in p38 linked cellular senescence of mouse embryonic fibroblasts," FEBS Letters, vol. 575, no. 1-3, pp. 30-34, 2004.

[24] A. Richmond and H. G. Thomas, "Melanoma growth stimulatory activity: isolation from human melanoma tumors and characterization of tissue distribution," Journal of Cellular Biochemistry, vol. 36, no. 2, pp. 185-198, 1988.

[25] M. Fukuoka, Y. Ogino, H. Sato, et al., "RANTES expression in psoriatic skin, and regulation of rantes and IL-8 production in cultured epidermal keratinocytes by active vitamin $\mathrm{D}_{3}$ (tacalcitol)," British Journal of Dermatology, vol. 138, no. 1, pp. 63-70, 1998.

[26] T. J. Schall, "Biology of the RANTES/SIS cytokine family," Cytokine, vol. 3, no. 3, pp. 165-183, 1991.

[27] T. J. Schall, K. Bacon, K. J. Toy, and D. V. Goeddel, "Selective attraction of monocytes and T lymphocytes of the memory phenotype by cytokine RANTES," Nature, vol. 347, no. 6294, pp. 669-671, 1990.

[28] T. Yoshimura and E. J. Leonard, "Human monocyte chemoattractant protein-1: structure and function," Cytokines, vol. 4, pp. 131-152, 1992.

[29] Y. Jiang, D. I. Beller, G. Frendl, and D. T. Graves, "Monocyte chemoattractant protein-1 regulates adhesion molecule expression and cytokine production in human monocytes," Journal of Immunology, vol. 148, no. 8, pp. 2423-2428, 1992.

[30] M. Baggiolini and C. A. Dahinden, "CC chemokines in allergic inflammation," Immunology Today, vol. 15, no. 3, pp. 127-133, 1994.

[31] A. J. Valente, D. T. Graves, C. E. Vialle-Valentin, R. Delgado, and C. J. Schwartz, "Purification of a monocyte chemotactic factor secreted by nonhuman primate vascular cells in culture," Biochemistry, vol. 27, no. 11, pp. 4162-4168, 1988.
[32] B. J. Rollins, A. Walz, and M. Baggiolini, "Recombinant human MCP-1/JE induces chemotaxis, calcium flux, and the respiratory burst in human monocytes," Blood, vol. 78, no. 4, pp. 1112-1116, 1991.

[33] S. R. Williams, Y. Jiang, D. Cochran, G. Dorsam, and D. T. Graves, "Regulated expression of monocyte chemoattractant protein-1 in normal human osteoblastic cells," American Journal of Physiology, vol. 263, no. 1, pp. C194-C199, 1992.

[34] R. Paus, T. Rosenbach, N. Haas, and B. M. Czarnetzki, "Patterns of cell death: the significance of apoptosis for dermatology," Experimental Dermatology, vol. 2, no. 1, pp. 311, 1993. 

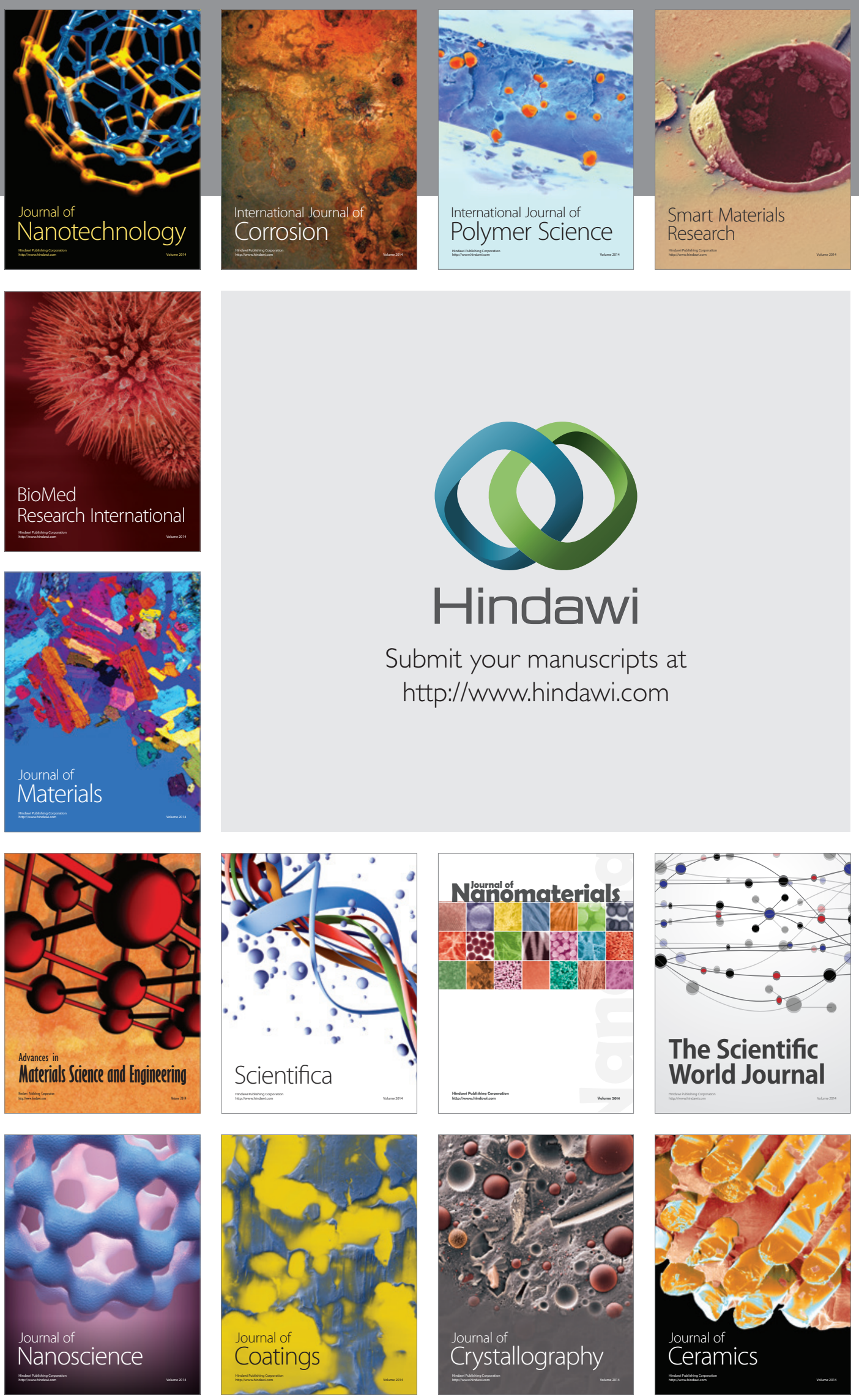

The Scientific World Journal

Submit your manuscripts at

http://www.hindawi.com

\section{World Journal}

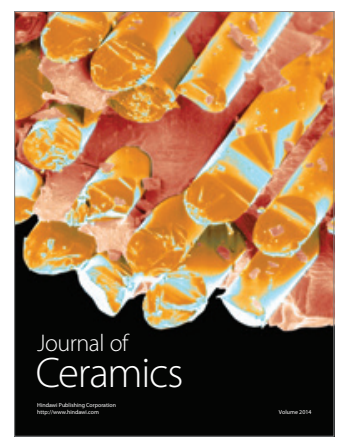

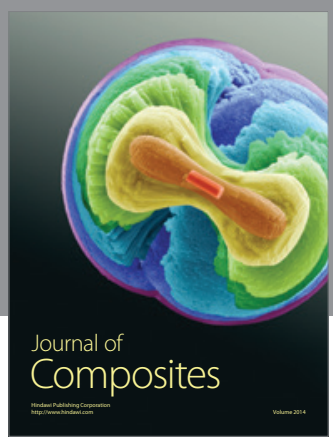
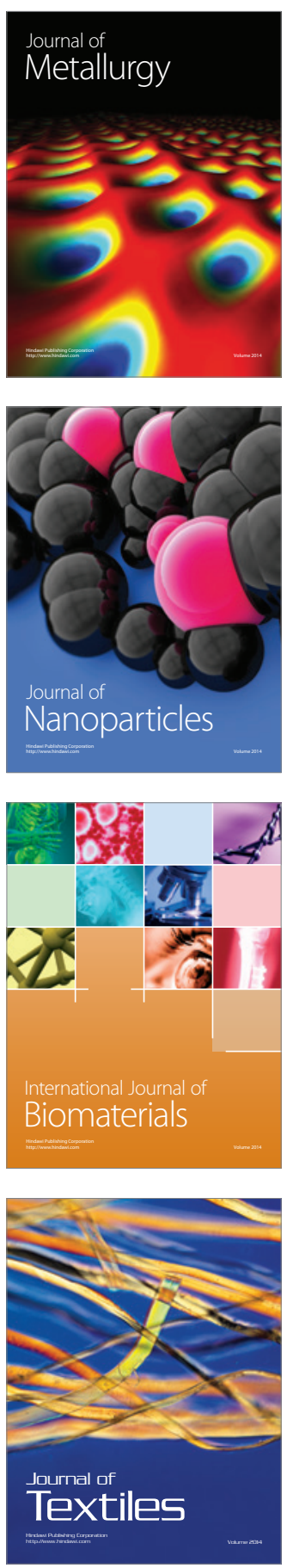